\title{
Evaluation of polymerase chain reaction in the routine diagnosis for tegumentary leishmaniasis in a referral centre
}

\author{
Aline Fagundes ${ }^{1 /}{ }^{+}$, Armando Schubach ${ }^{1}$, Cíntia Cristiane de Paula ${ }^{1}$, Alessandra Bogio ${ }^{1}$, \\ Liliane de Fátima Antonio', Patrícia Botelho Schiavoni', Vivian de Souza Monteiro', \\ Maria de Fátima Madeira', Leonardo Pereira Quintella², Claudia Maria Valete-Rosalino', \\ Erica de Camargo Ferreira e Vasconcellos ${ }^{1}$, Rilza Beatriz Gayoso de Azeredo-Coutinho ${ }^{3}$, \\ Rachel S Pacheco ${ }^{4}$, Mauro CA Marzochi', Keyla BF Marzochi ${ }^{1}$
}

'Laboratório de Vigilância em Leishmanioses ${ }^{2}$ Serviço de Anatomia Patológica, Instituto de Pesquisa Clínica Evandro Chagas ${ }^{3}$ Laboratório de Imunoparasitologia ${ }^{4}$ Laboratório de Sistemática e Bioquímica, Instituto Oswaldo Cruz-Fiocruz, Av. Brasil 4365, 21045-900 Rio de Janeiro, RJ, Brasil

The present study investigated the diagnostic value of polymerase chain reaction (PCR) performed in parallel to conventional methods at an American tegumentary leishmaniasis (ATL) referral centre for diagnosis. Accuracy parameters for PCR were calculated using 130 patients with confirmed ATL (ATL group), 15 patients established with other diseases and 23 patients with a lesion suggestive of ATL, but without parasitological confirmation (NDEF group). PCR showed $92.3 \%$ sensitivity, $93.3 \%$ specificity, a $99.2 \%$ positive predictive value and a 13.84 positive likelihood ratio. In the NDEF group, PCR confirmed ATL in 13 of the 23 patients, seven of whom responded to leishmaniasis treatment and six who presented spontaneous healing of the lesion. PCR should be included in the routine diagnostic procedures for ATL, especially for cases found to be negative by conventional methods.

Key word: Leishmania - polymerase chain reaction - diagnosis

The classical aetiological diagnosis of American tegumentary leishmaniasis (ATL) is made by isolation of the promastigotes forms of Leishmania in culture or by visualisation of amastigote forms in histopathological sections or in Giemsa-stained imprints. These procedures cannot be automated and are therefore difficult to standardise. Each technique has varying sensitivity and mainly depends on the number of parasites and other factors, such as the experience of the responsible technician, Leishmania species involved, clinical form and duration of the lesion. At primary health care services, patients with lesions suggestive of ATL and a positive Montenegro skin test (MST) are usually subjected to treatment with pentavalent antimonials, even in the absence of parasitological confirmation (MS 2006). Thus, semi-automated or automated diagnostic methods that could be easily standardised are beneficial.

Various studies have suggested the usefulness of molecular techniques for the aetiological diagnosis of ATL (Pirmez et al. 1999, de Oliveira et al. 2003, Schonian et al. 2003, Garcia et al. 2004, Marques et al. 2006, Gomes et al. 2008, Luz et al. 2009). In dif-

$\overline{\text { Financial support: FIOCRUZ (PAPES, IPEC), CNPq, FAPERJ-RJ, }}$ Brazilian Ministry of Health

+ Corresponding author: aline.fagundes@ipec.fiocruz.br

Received 28 July 2009

Accepted 21 December 2009 ferent studies conducted on humans, the sensitivity of the polymerase chain reaction (PCR) was about $100 \%$, whereas $60 \%$ was observed for other types of exams. However, these studies included patients with a diagnosis of ATL previously established by conventional techniques.

In the present study, we investigated the diagnostic value of PCR performed in parallel to conventional methods during the routine care of patients in an ATL referral centre for diagnosis, many of whom had presumptive diagnoses of ATL.

A trial of a diagnostic test was conducted to compare the PCR and exams routinely used for the diagnosis of ATL (imprint, histopathology and parasite isolation in appropriate culture from biopsy fragments). One hundred and sixty-eight patients presumed to have ATL were referred for diagnosis to the Laboratório de Vigilância em Leishmanioses, Instituto de Pesquisa Clínica Evandro Chagas (IPEC), Fiocruz, Rio de Janeiro, between March 21, 2005-March 21, 2006 and were included in the study. The project was approved by the Ethical Committee of IPEC (process 0024.0.009.000-04) and all patients signed a free informed consent form.

After clinical, dermatological and otorhinolaryngological evaluation, a cutaneous or mucosal lesion biopsy was obtained from all patients. The biopsy specimen was divided into several fragments. The first fragment was used to make Giëmsa-stained imprints and was then fixed in $10 \%$ buffered formalin, embedded in paraffin and stained with haematoxylin-eosin, PAS, Grocott and Ziehl-Neelsen for histopathological examination. The second fragment was cultured in enriched blood agar medium (NNN) for the detection 
of the presence of Leishmania promastigotes. Fragments were also processed for mycological examination and detection of mycobacteria.

Another fragment was placed in a dry Eppendorf tube and kept at $-20^{\circ} \mathrm{C}$ until the DNA extraction process. DNA was extracted with the Genomic Prep ${ }^{\circledR}$ kit (Amershan Biosciences, Upsalla, Sweden) according to the manufacturer's instructions. Extracted DNA was dried at RT and resuspended in $25 \mu \mathrm{L}$ TE buffer. Eight-10 samples were run in each DNA extraction.

PCR was performed using primers that amplify the conserved region of the minicircle molecule present in all Leishmania species. The reaction mixture contained $10 \mathrm{ng}$ of each primer $\left(5^{\prime}-{ }^{\prime}(\mathrm{G} / \mathrm{C})(\mathrm{G} / \mathrm{C})(\mathrm{C} / \mathrm{G}) \mathrm{CC}(\mathrm{A} / \mathrm{C})\right.$ CTAT(A/T)TTACACCAACCCC and 5'GGGGAGGGGCGTTCTGCGAA), $200 \mathrm{mM}$ dNTPs (Invitrogen, Carlsbad, California), 2.5 units Taq polymerase (Amplitaq Gold, Perkin-Elmer, Norwalk, CT) and $1.5 \mathrm{mM}$ $\mathrm{MgCl}_{2}$ in a final volume of $25 \mu \mathrm{L}$. A DNA volume of 5 $\mu \mathrm{L}$ was added to each test tube. The amplification reaction consisted of one cycle at $94^{\circ} \mathrm{C}$ for $10 \mathrm{~min}, 30$ cycles at $94^{\circ} \mathrm{C}$ for $30 \mathrm{~s}, 55^{\circ} \mathrm{C}$ for $30 \mathrm{~s}$ and $72^{\circ} \mathrm{C}$ for $30 \mathrm{~s}$ and a final step at $72^{\circ} \mathrm{C}$ for $10 \mathrm{~min}$. After the PCR, the amplified products were separated by horizontal electrophoresis in a $2 \%$ agarose gel stained with ethidium bromide for visualisation of the 120-bp band obtained after amplification. The previously defined detection threshold of the assay is $8.34 \mathrm{pg}$ DNA.

In each amplification, a negative control sample without DNA and a positive control sample containing 10 pg DNA extracted from an axenic culture of Leishmania (Viannia) braziliensis were added. Two amplifications were run per sample. In the case of discordant results, PCR was repeated and findings that were concordant in two experiments were considered as the final result. All PCR-negative samples were reamplified after the addition of $1 \mu \mathrm{L}$ DNA extracted from an axenic culture of $L$. $(V$.) braziliensis to determine the presence of PCR inhibitors. The molecular detection tests were carried out independently from the other exams used for the routine diagnosis of ATL.

The results of the molecular tests were analysed using the Epi-Info (CDC, Washington, USA) and SPSS 11.0 software packages (IBM-SPSS Inc Chicago, USA). Differences were considered as significant when $p<$ 0.05 . Proportions related to dichotomous variables were compared by Pearson's chi-square $\left(\chi^{2}\right)$ test and Fisher's exact test. Continuous variables were analysed after evaluation of their distribution using histograms and box plots. Additionally, the parametric Mann-Whitney test was chosen for comparison of means between two independent groups. The Kruskal-Wallis test was used when comparing three or more groups. Sensitivity, specificity and predictive values of PCR were calculated using the Epitable module of the Epi-Info 6.0 software.

Among the 168 patients studied, 130 (77.4\%) were diagnosed with ATL based on the outcomes of one or more of the following exams: imprint, culture and histopathology (ATL group); 15 (8.9\%) presented a lesion of other aetiology (NATL group) and 23 (13.7\%) presented a lesion suggestive of ATL but without parasitological confirmation (NDEF group). PCR was positive for 134 patients: $120(92.3 \%, \mathrm{n}=130)$ in the ATL group, one $(6.6 \%, \mathrm{n}=15)$ in the NATL group and $13(56.5 \%, \mathrm{n}=$ 23 ) in the NDEF group. In contrast, 10 patients presented a negative PCR despite another positive exam for ATL. Out of the 134 PCR-positive cases, 119 (88.9\%) occurred in patients living in endemic areas for ATL (Pearson's $\chi^{2}=11.612, p=0.007$ ).

In the ATL group, $115 / 130$ patients $(88.5 \%)$ had the cutaneous form and 15/130 (11.5\%) had the mucocutaneous form of the disease. PCR was positive in 14 of the 15 patients with the mucocutaneous form $(93.3 \%$ positivity) and in 106 of the 115 patients with the cutaneous form ( $92.1 \%$ positivity). The performance of the test was similar for both clinical forms of the disease (Pearson's $\chi^{2}=0.020, p=0.888$ ).

Patients in the NATL group $(\mathrm{n}=15)$ had the following diagnoses: squamous cell carcinoma $(n=4)$, sporotrichosis $(n=3)$, leprosy $(n=1)$, lentigo $(n=1)$, pyodermitis $(n=1)$ and vascular ulcer $(n=5)$. Seven of these patients lived in endemic ATL areas, including the only patient of this group who tested positive by PCR.

On the basis of the PCR results obtained for the ATL and NATL groups, the sensitivity, specificity, predictive values, likelihood ratio and pre and post-test probabilities of the test were calculated (Table), which established the potential usefulness of PCR in the diagnostic investigation of patients in the NDEF group.

The NDEF group consisted of $15(65.3 \%)$ patients whose lesions healed spontaneously during the diagnostic investigation and eight (34.7\%) patients from an endemic area who had suggestive ATL lesions without parasitological confirmation, but with a favourable response to the meglumine antimoniate treatment. Ten of the 13 patients in this group lived in ATL endemic areas. PCR was positive for six of the 15 patients who developed spontaneous healing and for seven of the eight patients with a favourable response to the antimonial

\section{TABLE}

Validation of polymerase chain reaction (PCR) for patients with diagnosis of American tegumentary leishmaniasis or with other diagnoses

\begin{tabular}{lcc}
\hline Parameter & & $95 \% \mathrm{CI}$ \\
\hline Sensitivity & $92.3 \%$ & $0.87-0.96$ \\
Specificity & $93.3 \%$ & $0.80-1.05$ \\
Positive predictive value & $99.2 \%$ & $0.97-1.00$ \\
Negative predictive value & $58.3 \%$ & $0.38-0.78$ \\
Likelihood ratio for a positive test & 13.84 & $2.08-92.04$ \\
Likelihood ratio for a negative test & 0.08 & $0.04-0.15$ \\
Pre-test probability & 0.89 & - \\
Pre-test chance & 8.09 & - \\
Post-test chance & 105.1 & - \\
Post-test probability & 0.99 & - \\
\hline
\end{tabular}


treatment. The positive predictive value and post-test probability defined in Table permit the attribution of a diagnostic value to the positive PCR results obtained in the NDEF group. Thus, PCR increased the number of ATL cases diagnosed among the studied 168 patients from $130(77.4 \%)$ to $143(85.1 \%)$.

In the present study, the combination of imprint, histopathology and culture was used as the standard for the definition of ATL, with which we were able to diagnose the disease in 130 (ATL group) of the 168 patients studied. The sensitivity of each exam was $23 \%, 35.3 \%$ and $81.5 \%$ for imprint, histopathology and culture, respectively. Similar results have been reported by other investigators who attributed this variation in sensitivity to different factors, including duration of the disease, sampling methods and processing of the biological samples (Aviles et al. 1999, Ramirez et al. 2000, Culha et al. 2006). PCR was the most sensitive and specific exam among the applied methods. These findings were in agreement with other Brazilian studies using the same or different primers (Pirmez et al. 1999, Romero et al. 2001, Oliveira et al. 2005, Marques et al. 2006).

In contrast to other PCR evaluation studies of patients with ATL diagnosis, the present study compared PCR with other methods carried out in parallel during the diagnostic investigation of patients receiving care at an ATL referral centre. The low negative predictive value of PCR was likely influenced by the high prevalence of ATL in the sample studied. This finding suggested that the higher the prevalence, the lower the negative predictive value and the higher the positive predictive value would be. The accuracy parameters defined for PCR were used to determine the potential diagnostic value of this technique for the investigation of the 23 patients without a diagnostic confirmation of ATL by the gold standard.

Over the last 12 years, only three cases of spontaneous regression were documented at referral centre in patients who refused treatment using conventional techniques. All of these patients presented successive phases of lesion reactivation and remission over various months. However, our present findings suggest that ATL lesions may progress to spontaneous healing over a relatively short period of time, simulating other diseases as bacterial infections or sporotrichosis (Schubach et al. 2008).

The patient PCR-positive in NACL group was a 57-year-old man with a well-differentiated epidermoid carcinoma. Re-evaluating his records after the PCR results, we found that he lived in an endemic area of visceral and cutaneous leishmaniasis at the time of diagnosis. Further tests revealed a negative MST and a positive serology for Leishmania up to a dilution of 1:160 by indirect immunofluorescence. The PCR was repeated in another laboratory with a different DNA aliquot and with other primer pairs, specific for Viannia subgenus and the positive result was also confirmed by molecular hybridisation using an L. (V.) braziliensis (MHOM/BR/1975/ M2903) kDNA probe that was radioactively labelled with 32P dCTP according to Pacheco et al. (2000) (data not shown). Because a positive PCR does not differenti- ate a past leishmaniasis infection from an active one, it should be possible, although unlikely, that this patient could be subclinically infected with Leishmania, as also suggested by Brustoloni et al. (2007).

In conclusion, because of the accuracy parameters encountered for the PCR in this study, a routine procedure for both confirmed and suspicious patients should include PCR in the diagnostic procedures of referral centres for ATL. This PCR method should also be applied for specially indicated cases that test negative by conventional exams used for aetiological diagnosis. However, PCR should not substitute the other exams for leishmaniasis diagnosis because a routine protocol should employ more parameters if possible, including specific exams, clinical features, MST and epidemiological history of the patient.

\section{ACKNOWLEDGEMENTS}

To all the patients of the study and to the entire staff of the Laboratório de Vigilância em Leishmanioses, IPECFiocruz, and to Dra. Maria Inês Pimentel, for the English review of the manuscript.

\section{REFERENCES}

Aviles H, Belli A, Armijos R, Monroy FP, Harris E 1999. PCR detection and identification of Leishmania parasites in clinical specimens in Ecuador: a comparison with classical diagnostic methods. J Parasitol 85: 181-187.

Brustoloni YM, Lima RB, da Cunha RV, Dorval ME, Oshiro ET, de Oliveira AL, Pirmez C 2007. Sensitivity and specificity of polymerase chain reaction in Giemsa-stained slides for diagnosis of visceral leishmaniasis in children. Mem Inst Oswaldo Cruz 102: 497-500.

Culha G, Uzun S, Ozcan K, Memisoglu, HR, Chang KP 2006. Comparison of conventional and polymerase chain reaction diagnostic techniques for leishmaniasis in the endemic region of Adana, Turkey. Int J Dermatol 45: 569-572.

de Oliveira CI, Bafica A, Oliveira F, Favali CB, Correa T, Freitas LA, Nascimento E, Costa JM, Barral A 2003. Clinical utility of polymerase chain reaction-based detection of Leishmania in the diagnosis of American cutaneous leishmaniasis. Clin Infect Dis 37: e149-153.

Garcia L, Kindt A, Bermudez H, Llanos-Cuentas A, De Doncker S, Arevalo J, Wilber Quispe Tintaya K, Dujardin JC 2004. Cultureindependent species typing of neotropical Leishmania for clinical validation of a PCR-based assay targeting heat shock protein 70 genes. J Clin Microbiol 42: 2294-2297.

Gomes AH, Armelin IM, Menon SZ, Pereira-Chioccola VL 2008. Leishmania (V.) braziliensis: detection by PCR in biopsies from patients with cutaneous leishmaniasis. Exp Parasitol 119: 319-324.

Luz ZM, Silva AR, Silva FO, Caligiorne RB, Oliveira E, Rabello A 2009. Lesion aspirate culture for the diagnosis and isolation of Leishmania spp from patients with cutaneous leishmaniasis. Mem Inst Oswaldo Cruz 104: 62-66.

Marques MJ, Volpini AC, Machado-Coelho GL, Machado-Pinto J, da Costa CA, Mayrink W, Genaro O, Romanha AJ 2006. Comparison of polymerase chain reaction with other laboratory methods for the diagnosis of American cutaneous leishmaniasis: diagnosis of cutaneous leishmaniasis by polymerase chain reaction. Diagn Microbiol Infect Dis 54: 37-43.

MS - Ministério da Saúde, Brasil 2006. Manual de controle da leishmaniose tegumentar americana, Ministério da Saúde, Brasília DF, 182 pp. 
Oliveira JG, Novais FO, de Oliveira CI, da Cruz Junior AC, Campos LF, da Rocha AV, Boaventura V, Noronha A, Costa JM, Barral A 2005. Polymerase chain reaction (PCR) is highly sensitive for diagnosis of mucosal leishmaniasis. Acta Trop 94: 55-59.

Pacheco RS, Fernandes O, Salinas G, Segura I, Momen H, Degrave W, Saravia NG, Campbell DA 2000. Intraspecific heterogeneity in the mini-xon gene localization of Leishmania $(V$.) panamensis and Leishmania (V.) guyanensis from Colombia. J Parasitol 86: $1250-1253$

Pirmez C, da Silva Trajano V, Paes-Oliveira Neto M, da-Cruz AM, Gonçalves-da-Costa SC, Catanho M, Degrave W, Fernandes O 1999. Use of PCR in diagnosis of human American tegumentary leishmaniasis in Rio de Janeiro, Brazil. J Clin Microbiol 37: $1819-1823$
Ramirez JR, Agudelo S, Muskus C, Alzate JF, Berberich C, Barker D, Velez ID 2000. Diagnosis of cutaneous leishmaniasis in Colombia: the sampling site within lesions influences the sensitivity of parasitologic diagnosis. J Clin Microbiol 38: 3768-3773.

Romero GA, Guerra MV, Paes MG, Cupolillo E, Bentin Toaldo C, Macedo VO, Fernandes O 2001. Sensitivity of the polymerase chain reaction for the diagnosis of cutaneous leishmaniasis due to Leishmania (Viannia) guyanensis. Acta Trop 79: 225-229.

Schonian G, Nasereddin A, Dinse N, Schweynoch C, Schallig HD, Presber W, Jaffe CL 2003. PCR diagnosis and characterization of Leishmania in local and imported clinical samples. Diagn Microbiol Infect Dis 47: 349-358.

Schubach A, Barros MB, Wanke B 2008. Epidemic sporotrichosis. Curr Opin Infect Dis 21: 129-133. 